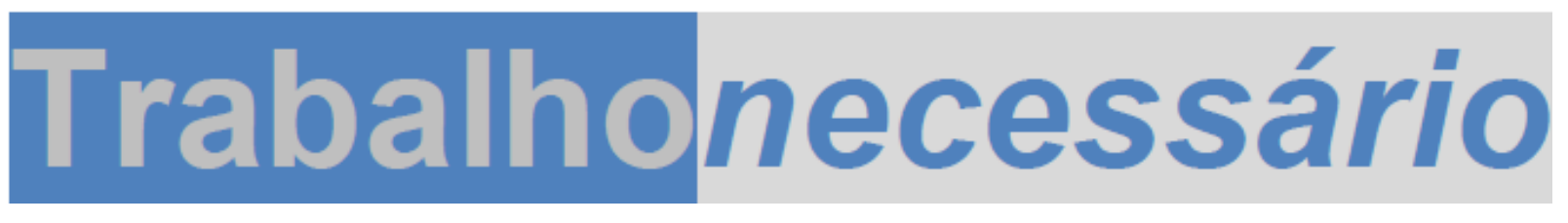

Issn: 1808 - 799X

ano 11, no $17-2013$

Resenha

\title{
PEDAGOGIA HISTÓRICO-CRÍTICA E LUTA DE CLASSES NA EDUCAÇÃO ESCOLAR
}

\author{
Sandra Maria Glória da Silva ${ }^{1}$ \\ sangloria@live.com \\ Maria Aparecida da Silva ${ }^{2}$ \\ masilva988@hotmail.com
}

\section{Resumo:}

Apresenta-se por meio desta resenha a obra "Pedagogia histórico-crítica e luta de classes na educação escolar" organizada por Dermeval Saviani e Newton Duarte e publicada pela Autores Associados na coleção Polêmicas do nosso tempo. Essa produção compõe-se por sete artigos selecionados com a finalidade de esclarecer os fundamentos da concepção marxista de educação visando solucionar as principais controvérsias originadas no campo marxista. Os autores desses textos são favoráveis à união de esforços em prol da militância pela superação da sociedade burguesa e consideram o acesso da classe trabalhadora aos conhecimentos científicos, artísticos e filosóficos elemento crucial nesse processo.

Palavras-chave: Pedagogia histórico-crítica. Teoria marxista e educação. Controvérsias no marxismo.

\footnotetext{
${ }^{1}$ Mestra e Especialista em Educação Tecnológica pelo Centro Federal de Educação Tecnológica de Minas Gerais (CEFET-MG), Pedagoga plena graduada pela Universidade do Estado de Minas Gerais (UEMG).

${ }^{2}$ Doutora em Educação pela Universidade Estadual de Campinas (Unicamp), professora no Mestrado em Educação Tecnológica do CEFET-MG, docente e coordenadora do Programa Especial de Formação Pedagógica de Docentes no CEFET-MG, professora aposentada da Universidade Federal de Minas Gerais (UFMG).
} 


\section{Trabalhonecessário}

Issn: 1808 - 799X

ano 11, no $17-2013$

\section{Abstract:}

We present by means of this review the work "Historical-critical pedagogy and class struggle in school education" organized by Dermeval Saviani and Newton Duarte and published by Autores Associados in the collection Polemics of our time. This production consists of seven papers selected in order to clarify the foundations of Marxist education and resolving major disputes arising in the Marxist camp. The authors of these texts are in favor of union militancy efforts to overcome the bourgeois society and consider the working class access to scientific, artistic and philosophical knowledges crucial element in this process.

Keywords: Historical and critical pedagogy. Marxist theory and education. Controversies in Marxism. 


\section{Trabalhonecessário}

Issn: 1808 - 799X

ano 11, no $17-2013$

Dermeval Saviani, professor emérito da Universidade Estadual de Campinas (Unicamp) e coordenador geral do Grupo Nacional de Estudos e Pesquisas "História, Sociedade e Educação no Brasil" (Histedbr), e Newton Duarte, doutor em educação pela Unicamp, livre-docente e professor titular pelo departamento de psicologia da educação da Faculdade de Ciências e Letras da Universidade Estadual Paulista Júlio de Mesquita (Unesp), campus de Araraquara, coordenador do Grupo de Pesquisa "Estudos Marxistas em Educação", organizaram o livro "Pedagogia histórico-crítica e luta de classes na educação escolar" com o propósito de "[...] esclarecer as bases educativas da concepção marxista como ponto de partida para dirimir as controvérsias que têm se manifestado no interior do campo do próprio marxismo [...]" (SAVIANI; DUARTE, 2012, p. 10) e unir esforços em prol do fortalecimento de movimentos contra-hegemônicos visando à construção de uma nova sociedade.

Os sete artigos selecionados por Saviani e Duarte (2012) foram ordenados com vistas a contemplar os seguintes aspectos: a) apresentar a formação humana na perspectiva histórico-ontológica; b) explicitar a relação entre ontologia do ser social e pedagogia histórico-crítica; c) expor a articulação entre marxismo, educação e pedagogia; d) responder objeções e dissipar equívocos a respeito do posicionamento teórico assumido pelos organizadores; e e) evidenciar os vínculos entre luta de classes, educação e revolução visando reduzir divergências entre os que lutam pela superação da ordem social vigente.

A tese central do livro consiste na afirmação de que "[...] a luta pela escola pública coincide com a luta pelo socialismo" (SAVIANI; DUARTE, 2012, p. 2). Conforme Saviani e Duarte (2012), essa tese origina-se da análise de uma contradição existente na história da educação escolar, qual seja: a escola é o espaço legitimado para difusão do conhecimento sistematizado pela humanidade. Porém, na sociedade capitalista, o conhecimento faz parte dos meios de produção e não pode ser socializado, pois é propriedade do capital. Segundo Saviani e Duarte (2012), as contradições, na perspectiva da dialética, em vez de 


\section{Trabalhonecessário}

Issn: 1808 - 799X

ano 11, no $17-2013$

gerar imobilismos, produzem movimento. Então, esses autores recorrem à dialética para apontar no mínimo duas possíveis direções em que a contradição da difusão do conhecimento na sociedade capitalista pode mover-se, a saber: uma favorável aos desejos da classe dominante, outra em consonância com os anseios da classe trabalhadora.

Saviani e Duarte (2012) afirmam que o pleno acesso da classe trabalhadora aos conhecimentos científicos, artísticos e filosóficos ainda não é possível na sociedade burguesa e salientam o valor da luta pela plena socialização. Esses autores esclarecem que essa luta sozinha não revolucionará a sociedade, mas a educação constitui-se em importante campo estratégico.

No primeiro capítulo, Dermeval Saviani e Newton Duarte, ao discutirem "A formação humana na perspectiva histórico-ontológica", abordam as ideias que atualmente predominam na educação, articulando-as à crise de paradigmas nas ciências sociais. Em seguida, apontam lacunas no "[...] neopragmatismo que hoje busca reabilitar o pragmatismo alçando-o, pela via da filosofia analítica, à condição de pensamento hegemônico [...]" (SAVIANI; DUARTE, 2012, p. 19). Por fim, apontam o estudo crítico dos clássicos da filosofia como condição indispensável à formação humana. Esses autores esclarecem que o clássico define-se pela permanência e referência, sem coincidir com o tradicional nem contrapor-se ao moderno.

No segundo capítulo, "Lukács e Saviani: a ontologia do ser social e a pedagogia histórico-crítica", Newton Duarte evidencia a ausência de tentativas de aproximação entre esses dois campos e considera que a "[...] aproximação entre Lukács e Saviani pode também ser enriquecida pela aproximação entre Lukács e Vigotski" (DUARTE, 2012, p. 55). Conforme Duarte (2012), apreende-se a essência ontológica da educação a partir de uma perspectiva historicista. Nesse sentido, uma ontologia da educação tem por finalidade compreender o processo pelo qual os indivíduos se tornam seres sociais. Além disso, "para que uma teoria marxista da educação possa ser também uma pedagogia marxista, é necessário 


\section{Trabalhonecessário}

Issn: 1808 - 799X

ano 11, no $17-2013$

assumir um posicionamento afirmativo sobre o que significa educar seres humanos hoje." (DUARTE, 2012, p. 41).

Dermeval Saviani articula no terceiro capítulo a tríade "Marxismo, educação e pedagogia" por meio da relação entre teoria marxista e pedagogia socialista. Nesse processo, o autor distingue as principais acepções de socialismo, explicita o significado do conhecimento em Marx, apresenta passagens e estudos sobre teoria marxista e educação. Além disso, salienta que a expressão pedagogia socialista utilizada como orientação pedagógica condizente com a perspectiva marxista justifica-se apenas em

"[...] períodos de transição entre a forma social capitalista com a correspondente pedagogia burguesa e a forma social comunista na qual - e apenas nela - será possível emergir uma pedagogia propriamente marxista, vale dizer, uma pedagogia comunista" (SAVIANI, 2012, p. 75).

Em seguida, Saviani (2012) sintetiza os "princípios filosóficos da pedagogia socialista" explicitados por Bogdan Suchodolski na obra "Fundamentos da Pedagogia Socialista", depois apresenta uma pedagogia concreta, isto é, embasada na pedagogia socialista e acrescida pela "[...] orientação marxista, porque baseada na teoria do conhecimento elaborada por Marx que tem como categoria central a noção de concreto [...]" (SAVIANI, 2012, p. 78). Por fim, Saviani (2012) conclui que a construção de uma pedagogia de inspiração marxista requer apreender concepções fundamentais "de ordem ontológica, epistemológica e metodológica" do materialismo histórico dialético e reformular os processos pedagógicos, as instituições formadoras, os currículos escolares com vistas à movimentação de "[...] um novo éthos educativo voltado à construção de uma nova sociedade, uma nova cultura, um novo homem" (SAVIANI, 2012, p. 81).

No quarto capítulo, "A pedagogia histórico-crítica e o marxismo: equívocos de (mais) uma crítica à obra de Dermeval Saviani”, Duarte et al (2012) criticam a tese de doutorado intitulada "A relação entre capital e educação escolar na obra de Dermeval Saviani: apontamentos críticos" elaborada por Ademir Quintilio 


\section{Trabalhonecessário}

Issn: 1808 - 799X

ano 11, no $17-2013$

Lazarini sob orientação de Paulo Sérgio Tumolo e defendida na Universidade Federal de Santa Catarina, em 2010. Conforme Duarte et al (2012), entre os principais argumentos apresentados por Lazarini (2010) destaca-se a denúncia de apropriação equivocada das categorias da teoria marxista por parte de Dermeval Saviani e, por decorrência, a pedagogia histórico-crítica não seria socialista. Em seguida, Duarte et al (2012, p. 99) expõem a fragilidade dos argumentos de Lazarini (2010) e a consideram como "[...] consequência do caráter não dialético de sua compreensão do pensamento de Marx". Os autores apresentam ao longo do texto diversas citações tanto da tese de Lazarini (2010) como das produções de Saviani para demonstrar "[...] distorções que Lazarini faz do pensamento de Saviani" (DUARTE et al, 2012, p. 109).

No quinto capítulo, "Debate sobre educação, formação humana e ontologia a partir da questão do método dialético", Dermeval Saviani reafirma as principais teses da pedagogia histórico-crítica em resposta às críticas a essa pedagogia, originadas no campo marxista. Aponta, ainda, as novidades das críticas atuais e dirime os recorrentes equívocos e controvérsias. Saviani (2012) salienta que o esforço por ele empreendido na construção de uma teoria pedagógica alicerçada no marxismo originou-se da insatisfação dele com as produções que tratavam da educação a partir desse ângulo, "[...] já que uma teoria marxista da educação, e principalmente uma pedagogia marxista, não chegava a emergir dessas análises" (SAVIANI, 2012, p. 145). Diante disso, Saviani (2012) apoiou-se em elementos indiciários presentes nessas produções e perscrutou o trajeto realizado por seus autores pelas obras clássicas do marxismo para tentar "[...] elaborar a teoria de que sentia necessidade" (SAVIANI, 2012, p. 146). Saviani (2012) salienta que a pedagogia histórico-crítica é uma construção coletiva - não atribuindo a si mesmo a exclusividade no contínuo desenvolvimento dessa proposta - e conclama os que a criticam a aperfeiçoá-la e/ou superá-la "[...] no espírito da concepção do materialismo histórico que implica a superação por incorporação" (idem, ibdem). 


\section{Trabalhonecessário}

Issn: 1808 - 799X

ano 11, no $17-2013$

No sexto capítulo, Newton Duarte discute "Luta de classes, educação e revolução" em entrevista concedida à revista "Germinal: marxismo e educação em debate". O texto resultante dessa entrevista trata da avaliação feita por esse intelectual "[...] sobre a atual conjuntura, no âmbito das relações hegemônicas e das possibilidades abertas para a educação" (DUARTE, 2012, p. 149). Entre as principais respostas elaboradas por Duarte (2012) destacam-se aquelas em que 0 autor: a) analisa controvérsias no campo marxista acerca da relação entre escola e socialização do conhecimento em sua forma mais desenvolvida. Esse autor afirma que para alguns marxistas o conhecimento não é um meio de produção e, portanto, "[...] a luta pela socialização do conhecimento não é parte da luta pela socialização da propriedade dos meios de produção" (DUARTE, 2012, p. 153154). Duarte (2012) salienta que, tendo em vista a manutenção da estrutura social vigente, não interessa à classe dominante o acesso da classe trabalhadora aos conhecimentos produzidos e acumulados pela humanidade; b) esclarece a importância de desenvolver estudos e pesquisas sobre educação, na perspectiva do materialismo histórico-dialético, a partir das obras de autores que favoreçam a compreensão da "[...] educação escolar no contexto da luta de classes na atualidade" (DUARTE, 2012, p. 161); e c) salienta que a principal tarefa docente é "[...] dominar e transmitir aos seus alunos o conhecimento científico, artístico e filosófico em suas formas mais desenvolvidas" (DUARTE, 2012, p. 165).

No sétimo e último capítulo, Dermeval Saviani discorre sobre "História, trabalho e educação: comentários sobre as controvérsias internas ao campo marxista". Nesse texto, a principal questão colocada pelo autor é por que militantes de esquerda, em geral, e, particularmente, marxistas mantêm divergências na interpretação de aspectos práticos e/ou teóricos? "Que implicações tem esse fenômeno para o avanço da consciência dos militantes e para a luta revolucionária?" (SAVIANI, 2012, p. 167). Para Saviani (2012) é possível considerar salutar a existência de divergências interpretativas, pois "[...] a análise crítica e o debate das posições são um elemento integrante da tradição 


\section{Trabalhonecessário}

Issn: 1808 - 799X

ano 11, no $17-2013$

marxista, constituindo-se num procedimento crucial para refinar a teoria e as estratégias revolucionárias e para fazer avançar o conhecimento" (SAVIANI, 2012, p. 167-168). Para exemplificar essa assertiva, Saviani (2012) apresenta controvérsias nas quais os clássicos do marxismo se envolveram. Segundo esse autor, tanto as discussões realizadas por Marx e Engels como as promovidas por Lênin e Gramsci tiveram por eixo dois princípios, a saber: "[...] 1) a diferenciação entre a perspectiva proletária e aquela dos burgueses e pequenos burgueses progressistas; e 2) a firme união entre as forças que buscam expressar e fazer avançar a luta dos trabalhadores" (SAVIANI, 2012, p. 169). Saviani (2012) preconiza a união de esforços de integrantes do campo marxista em prol da luta pela transformação social. Nesse sentido, ressalta que o manifesto redigido por Marx e Engels foi "[...] do Partido Comunista e não [...] de um dos Partidos Comunistas. E o lema que fecha o Manifesto é exatamente: 'Proletários de todos os países, uni-vos!"' (SAVIANI, 2012, p. 172, grifo do autor).

Enfim, o livro "Pedagogia histórico-crítica e luta de classes na educação escolar" reúne textos densos elaborados por pesquisadores dedicados ao estudo do marxismo e educação e militantes na luta pelo socialismo. Por isso, recomenda-se essa obra aos discentes e docentes estudiosos da educação escolar em cursos de graduação e pós-graduação, especialmente aos que almejam possibilitar à classe trabalhadora 0 acesso aos mais elevados conhecimentos produzidos pela humanidade.

Data de recebimento: 30/04/2013 Data de aprovação 22/10/2013 